NOTAS

\title{
POÉTICA Y FICCIÓN EN ARISTÓTELES
}

Cecilia Sabido*

\begin{abstract}
RESUMEN: En este trabajo se considera la distinción entre historia y poesía en el pasaje 1451a 36-b 11, para sentar los límites de la verosimilitud poética y sus alcances en la contemplación de la prâxis y la verdad práctica. Se estudia para ello la relación entre la mímesis y la ficción como hipótesis de acciones.
\end{abstract}

PAlABRAS ClaVE: Aristóteles, poesía, ficción, mímesis, praxis.
ABSTRACT: In this article we delimitate the distinction between history and poetry in passage 1451a 36-b 11, in order to establish the limits of poetic verisimilitude and its usefulness in the exploration of praxis and practical truth. In order to do this, we study the relationship between mimesis and fiction as hypothesis for actions.

KEYWORDS: Aristotle, poetry, fiction, mimesis, praxis.

* Universidad Panamericana. 


\section{POÉTICA Y FICCIÓN EN ARISTÓTELES}

Aristóteles advierte en la Ética Nicomaquea que producción y acción son actividades distintas, tanto en sus fines como en las virtudes que les corresponden. Sin embargo, la Poética parte de la posibilidad de producir una acción. No en el sentido de llevarla a cabo, sino de re-presentarla miméticamente. La mimēsis, al soportar la tensión entre ambas actividades, abre un contexto peculiar que llamaré aquí "ficción". ${ }^{1}$

La ficción puede considerarse como el sitio de una acción, un terre-

${ }^{1}$ La versión original del artículo presenta los términos aristotélicos escritos en griego. He preferido transliterarlos aquí para facilitar su edición. Sigo para ello el modelo $A L A-L C$ publicado por R. K. Barry, Romanization Tables: Transliteration Schemes for Non-Roman Scripts, 1997, Library of Congress. http://www.loc.gov/catdir/cpso/romanization/ greek.pdf. 02.01.2010. no supuesto que permite establecer las posibilidades constructivas de la producción $\mathrm{y}$, a la vez, posibilita la ejecución de una acción una y entera, tal como Aristóteles afirma que debe ser la obra poética. La ficción constituye la realidad poética, esto es, el espacio hipotético en que se verifica la acción producida.

Al hablar de ficción no es posible eludir el problema de la relación entre la acción poética y la realidad. Podría pensarse que la poesía es irreal dado el espacio hipotético en el que se desarrolla; no obstante, sabemos que para Aristóteles lo posible es un modo de ser. ${ }^{2}$ Además, aquello que la poética presenta en la ficción no sólo tiene realidad en el reducido campo

\footnotetext{
${ }^{2}$ Metaph., V-7, $1017^{\mathrm{a}}$ 35-37.
} 
hipotético, sino que tiene la vocación de iluminar las posibilidades de la vida actual, puesto que la mimēsis tiene como fuente la realidad misma, y la ficción contribuye a citar la realidad como posibilidad. Ello hace de la poética una actividad elocuente en el descubrimiento de la realidad, especialmente en la vida humana.

Teniendo en cuenta la relación de la ficción con la realidad, se ha de considerar también la verdad de la poética en dos categorías, una intrínseca y otra manifiesta. La obra en sí misma exige una coherencia lógica, una economía de partes y una unidad intrínseca. Pero aquello que es verdadero ad intra tiene una vocación hacia la realidad como eikòs, verosimilitud, como la posibilidad de lo verdadero.

La ficción permite contemplar lo que puede ser verdadero en movimiento o en composición (que es el modo más adecuado para contemplar las realidades prácticas). ${ }^{3}$ Por la ficción, la poética permite conocer esa ver-

${ }^{3}$ Reconocer este rasgo de realidad "puesta en observación" en un contexto de ficción implica una dimensión práctica y no sólo fabril en el poeta. Aristóteles llega a considerar en el libro VIII de la Política la incidencia de la música y del arte en la educación del ciudadano, de modo que no puede sustraerse el arte de la vida política. (Pol., VIII-6, 1340b 20-25). No se trata de proponer un "arte de estado", sino que la perspectiva antropológica que interesa a este estudio, reconocer una dimensión práctica del arte implica el hecho de que el artista tiene una incidencia personal en la sociedad: su obra es, además de un objeto concreto, una acción política. dad que se hace verdad en la acción. Teniendo en cuenta la relación de la ficción con la realidad, en el presente trabajo se ha de considerar la distinción entre historia y poesía en el pasaje 1451a 36-b 11, para sentar los límites de la verosimilitud poética (katà tò eikòs) y sus alcances en la contemplación de la prâxis.

\section{La complejidad de la acción}

Aristóteles distingue la acción del hombre entre las acciones de los vivientes en general, por ser aquella que es "propia del ente que tiene razón". ${ }^{4}$ Por la complejidad intrínseca del alma humana, sin embargo, no es la razón lo único que interviene en la consecución de una acción humana: sólo se considera propiamente tal aquella que resulta de la elección voluntaria. ${ }^{5}$ La acción humana es, por tanto una dynamis compleja, que involucra no sólo la participación de diversas facultades del alma, sino que se desarrolla en un cierto tiempo. Implica, por tanto, un proceso, un movimiento. Por más que pueda estudiarse el modo en que las acciones humanas se estructuran, no es posible agotarlo, como bien advierte Aristóteles:

Quede convenido de antemano, sin embargo, que todo lo que se diga

${ }^{4} E N$, I-7, 1098a 3-5.

${ }^{5}$ Cfr. ibid., II-4, 1105a 30-b5. 
NOTAS

de las acciones debe decirse en esquema y no con rigurosa precisión. [...] En lo relativo a las acciones y a la conveniencia no hay nada establecido. $^{6}$

La razón que da Aristóteles a esta limitación en el análisis de las acciones humanas es que se ejecutan en un contexto concreto y particular. La ejecución concreta, así, depende de las circunstancias en que la acción se realiza y no hay modo de preverlas con precisión por dos razones: en primer lugar, porque "el fin de las acciones es relativo al momento"; en segundo, porque la acción depende de la voluntad de quien la ejecuta y por lo tanto puede realizarla o no hacerlo. ${ }^{7}$ Puede sorprender que el fin de la acción concreta dependa del momento, pero Aristóteles da de ello un ejemplo muy claro en el que un capitán de barco arroja al mar todos los tesoros que lleva para que no se hunda la embarcación en una tormenta. En principio, el capitán no habría querido deshacerse de sus tesoros, pero la tormenta y el peligro presentes cambian el fin y lo que conviene. ${ }^{8}$

Además, la acción humana es siempre una actividad mediata, esto es, mediada por la deliberación y

${ }^{6} E N, \mathrm{I}-2,1104$ a $1-4$.

${ }^{7}$ Cfr. ibid., III-1, 1110a 11-18.

${ }^{8}$ Ibid., III-1, 1110a 4-5. la elección. Por esta razón, hay que considerar la distancia entre lo que se quiere hacer y lo que se hace en realidad. Obtener el fin que se busca en un principio depende del modo en que la razón delibere sobre los medios adecuados y de la elección voluntaria, más la ejecución concreta. Las acciones humanas son susceptibles de error que puede ser tanto el no actuar en absoluto como el conseguir algo distinto a lo que se quería. En ocasiones, esta diferencia puede ser incluso mejor, como señala Aristóteles al hablar de la fortuna, pero puede obtenerse justo lo opuesto a lo que se pretendía.

Puede decirse que la acción es propiamente una "acción humana" por la participación de la razón y la voluntad en la elección con respecto a un fin, pero es la ejecución eficiente de la acción lo que hace que dicha acción sea real, en consecuencia, verdadera o falsa. ${ }^{9} \mathrm{Si}$ se pudieran sintetizar estos elementos, se diría que la elección es la clave distintiva de la acción humana, y la ejecución es la causa directa de su realidad. Por lo tanto, antes de la "ejecución concreta" todo lo que pueda decirse de la acción

${ }^{9}$ Es susceptible de verdad y falsedad. No sólo verdadero por ser existente (verdad ontológica), en especial porque el resultado puede ser distinto de lo que se quiere o puede ser obtenido de manera inadecuada (verdad práctica o técnica). También el hábito productivo puede estar acompañado de razón falsa (y el error puede estar en la intención o en la ejecución). 
es general, por ser más amplio, y no actual, sino posible:

Cuando se trata de acciones, lo que se dice en general tiene más amplitud, pero lo que se dice en particular es más verdadero porque las acciones se refieren a lo particular y es menester concordar con esto. $^{10}$

Como todo lo que puede ser de otra manera, existe una tensión entre la posibilidad y la realización de esa posibilidad. ${ }^{11}$ La perífrasis "lo que puede ser de otra manera" se expresa con un participio: endechómenon. ${ }^{12}$ Además, considerada en el campo de la actividad práctica, no se trata de una mera posibilidad, abierta sin más: se

${ }^{10} E N$, II-7, 1107a, 27-31. Lo general y posible contrasta con lo universal y necesario.

11 "Algo es actual si existe en completa realidad. El ser potencial carece de esta realidad, aunque nada imposible puede resultar si el ser potencial alcanza la actualidad de la que se dice que es capaz", F. Brentano, On the Several Senses of Being in Aristotle, 1981, Berkeley, University of California Press, pp. 29-30. (La traducción al castellano es mía).

${ }^{12}$ Esta palabra griega comúnmente se entiende como lo opuesto a la necesidad, como si se dijera "lo que no es necesario que ocurra". Pero en sí, la expresión no tiene una connotación negativa más que como un límite para la ciencia. Cuando Aristóteles habla de lo que es endechómenon en el ámbito práctico, denota un cierto tipo de realidad, cuya característica es la apertura, la posibilidad. Cfr. H. G. Liddell y R. Scott, A GreekEnglish Lexicon, 1940, Oxford, Clarendon Press, s.v. endechómenon. trata de una tendencia, una vocación hacia una realización concreta. ${ }^{13}$

$\mathrm{Al}$ ser endechómenon, las acciones humanas son estrictamente reales cuando se concretan. En cambio, la mimēsis de acciones humanas se concreta sólo en el ámbito poético. Aquí se descubre una diferencia importante entre poíesis y prâxis: al tratarse de un objeto externo a la acción, el fin de la actividad poética se distingue de la acción misma y no la concreta, porque muestra sólo la naturaleza posible de la acción. En este sentido, las obras poéticas son más generales que la historia, porque las realidades que en ella se dan cita siguen siendo abiertas y filosóficas. La verdad que se descubre en ellas es una verdad posible: es verosimilitud. De este modo, toda la versatilidad que Aristóteles encuentra en la actividad poética tiene, en su misma finalidad, una frontera, una circunscripción más o menos precisa. ${ }^{14}$ Esta afirmación resulta sorprendente cuando se toma en cuenta que, para Aristóteles, la poesía es más universal (kathólou) que la historia y resulta, por lo tanto, más filosófica.

La diferencia está en que uno dice lo que ha sucedido [el historia-

${ }^{13}$ Cfr. Brentano, op. cit., p. 31.

${ }^{14}$ Sobre la falacia de creer que por ser más universal es más "científica" la poesía, en el sentido "positivista" de la palabra, previene St. Croix en su ensayo "Aristotle on History and Poetry", en A. O. Rorty (ed.), Essays on Aristotle's Poetics, 1992, Oxford, Princeton University Press, pp. 23-32. 
NOTAS

dor] y otro lo que ha de suceder [el poeta]. Por esto también la poesía es más filosófica y elevada que la historia; pues la poesía dice más bien lo general y la historia, lo particular. En general a qué tipo de hombres les ocurre decir o hacer tales o cuales cosas verosímil o necesariamente, que es a lo que tiende la poesía, aunque luego ponga nombres a los personajes, y en particular, qué hizo o qué le sucedió a Alcibíades. ${ }^{15}$

En realidad, esta afirmación tan debatida del capítulo 9 de la Poética reconoce en la actividad poética un límite respecto de la naturaleza de las acciones humanas: "Resulta claro, por lo expuesto, que no corresponde al poeta decir lo que ha sucedido, sino lo que podría suceder, esto es, lo posible según la verosimilitud o la necesidad". ${ }^{16}$ Así, si el poeta tomara una acción histórica como pretexto de la acción mimética, no lo haría como acción histórica, sino como acción posible. ${ }^{17}$ Esto obliga a con-

${ }^{15}$ Po., 9, 1451b 4-11.

${ }^{16}$ Po., 9, 1451a 36-38. No se trata de negar que el poeta parta de una realidad histórica o que la cite; sucede que no lo hará al modo en que lo hace un historiador porque su intención es otra. Para el poeta, aun la historia puede formar parte de la mimēsis de una acción por su carácter de posibilidad.

${ }^{17}$ De algún modo, la zona de lo posible es mayor que la de la realidad efectiva, de modo que "lo posible es el fondo sobre lo que se recorta lo real". J. Vicente Arregui, "La verdad en la literatura", en Nuestro Tiempo, 478, 1994, p. 117. siderar la diferencia entre el sentido científico que se atribuye a la palabra kathólou, "universal", y su sentido aplicado a lo contingente, que se expresa como "en general" (hos epí tò poly). Puede decirse así, en cierto modo, que el kathólou de la poética es un kathólou en potencia. ${ }^{18}$

\section{El universal poético}

El límite mismo de "lo general" en la Poética está dado por el carácter potencial de lo kathólou que hay en ella, porque para Aristóteles tiene prioridad lógica y ontológica lo que es en acto. Sin embargo, este mismo carácter adquiere otro sentido desde dentro, desde "la obra en acto". En este tema radica la verdad de la obra ad intra y su verosimilitud ad extra. ${ }^{19}$

Además, en su ser "uno y entero" lo poético no puede -ni debe- abarcar la totalidad de lo real; primero, porque sería imposible, ya que la realidad y sus relaciones son inagotables; y segundo, porque una obra así no daría lugar a visibilidad alguna. Por otro lado, ¿qué podría motivar al poeta a transcribir o citar hechos históricos en su obra? Según Aristóteles, tal cita tendría lugar sólo en cuanto que lo real es verosímil por-

${ }^{18}$ Cfr. R. Yepes, La doctrina del acto en Aristóteles, 1993, Pamplona, Eunsa, pp. 372-3.

${ }^{19}$ Cfr. ibid., p. 373. 
que ya ha sucedido y su posibilidad está, por así decirlo, probada. ${ }^{20}$

Al mantener el carácter de "posibilidad", la mimēsis, referida a la acción libre nunca es copia. Es una reproducción porque cada acción, al ser representada, verdaderamente presenta una acción que se realiza en ese instante, es decir, es una acción real, pero su contexto es ficticio. ${ }^{21}$ La intencionalidad de la acción es ficticia y tiene su punto de partida, su desarrollo y su final dentro de ese contexto. La dimensión "ficticia" distingue radicalmente las acciones poéticas de las acciones en el contexto real o natural de la vida humana. ${ }^{22}$ En cierto modo,

20 "Y si en algún caso trata cosas sucedidas, no es menos poeta; pues nada impide que algunos sucesos sean tales que se ajusten a lo verosímil y a lo posible, que es el sentido en que los trata el poeta". Po., 9, 1451b 29-32.

${ }^{21}$ Lamarque propone que los "mundos imaginarios" mantienen una doble perspectiva: una interna y otra externa. Señala un ejemplo afortunado: ¿Quién creó a Frankenstein, el monstruo? El doctor Víctor Frankenstein, por supuesto. Esa es la respuesta desde la perspectiva interna. Desde la perspectiva externa se debía responder: Mary Shelley. P. Lamarque, "In and Out of Imaginary Worlds", en D. Knowles and J. Skorupski (eds.), Virtue and Taste, Essays on Politics, Ethics and Aesthetics, 1993, Oxford, Blackwell, p. 145.

${ }^{22} \mathrm{Al}$ mismo tiempo la ficción permite la contemplación del desarrollo de la acción. De hecho, hacer visible el proceso que implica una acción es ya, en sí misma, una cualidad que no posee la acción real. La ficción logra poner ante la vista esta dimensión. Woodruff señala que el contexto ficticio es una característica ineludible de la mimēsis. "The audience does know that nothing truly painful or destructive is taking place in stage; otherwise they could not take pleasure in the performance." $\mathrm{P}$. para que la obra consiga su fin es indispensable que mantenga ese margen.

Esta perspectiva de la ficción es más "obvia" en artes como el teatro, el cine, la danza, donde el espectador suele ser más consciente del contexto ficticio de lo que contempla. En las artes constructivas y plásticas, la referencia al sentido de mimēsis como acción real se desdibuja porque lo primero que se pone "ante la vista" es su carácter de obra en el sentido de érgon. Pero no por ello se debe rendir ante la tentación de entender la mimēsis como simple copia. La fuerza activa de la mimēsis es primordial y manifiesta en ellas. De hecho, basta con saber que ese objeto no tiene en sí mismo su punto de partida y acusa la necesidad de un agente. Difícilmente hay un "engaño" malintencionado como aquél contra el que, en cierto momento parece advertir Platón en la República. ${ }^{23}$ Esto permite comprender que la "ficción mimética" pertenece antes que nada al ámbito de la producción y por ello permanece en la realidad constituida de la obra. ${ }^{24}$

Woodruf, "Aristotle on Mimēsis", en A. O. Rorty, op. cit., p. 84.

${ }^{23} \mathrm{Pl}$., R., X, 596d.

${ }^{24}$ Cuando leí una conferencia relacionada con esta investigación, el doctor Alejandro Vigo planteó una objeción. Contaba acerca de una mujer mayor que, viendo una representación teatral, creyó que realmente los actores estaban peleando e intentó 
NOTAS

Lo que evidencia esta dimensión ficticia es la vertiente dinámica de la mimèsis poética referida a las acciones. Por un lado, la acción se renueva. Por otro lado, lo hace de modo general y no particular, de modo que no puede tratarse de una prâxis humana sin más. La tensión entre la acción práctica y la poética puede comprobarse al recordar dos textos aristotélicos: primero, Aristóteles ha dicho en la Ética Nicomaquea que la acción es más verdadera cuando es particular, y que todo cuanto se diga de la acción tiene un sentido general. ${ }^{25} \mathrm{Sin}$ embargo, en la Poética -como acaba de señalarse-, afirma que la poesía es más filosófica por ser general.

Aristóteles no niega la verdad que hay en la historia: es verdadera en cuanto acción porque se ha concretado y es real. ${ }^{26}$ En cambio, admite intervenir. En ese caso falla lo que la tradición teatral llama "convención": el hecho de que uno sea consciente de que lo que ve es ficticio. El hecho prueba que la acción vista era real en cierto modo, como la señora atestiguó, pero no en el sentido que ella interpretó. Que la confusión haya sido graciosa para los espectadores y para quienes escuchamos la historia muestra la validez que damos a la ficción. De hecho, la anécdota podría haber sido un ejemplo inventado por el doctor Vigo y ser igualmente válida para plantear su objeción.

${ }^{25} E N$, II-7, 1107a, 27-31. Lo que se dice de la acción no es igual que hacer una acción. Lo dicho sobre la acción no tiene la concreción de la acción realizada.

${ }^{26}$ La historia es una fuente y ejemplo de verdad práctica. Sobre la importancia que Aristóteles concede a la historia, contra la intepretación que la hace aparecer opaca ante la poesía, St. Croix escribe un interesante análisis que distingue el universal se- que hay un modo de presentar la acción posible de un modo más general y esto es filosófico. Sólo que, curiosamente, esta generalidad se manifiesta mediante personajes con un nombre y circunstancias particulares. Así, resulta que la acción humana puede presentarse de un modo a la vez universal y particular. Eso permite que se conserve lo propio de la acción (el actuar en concreto) en un ejercicio de ficción. De otro modo, el poeta sólo diría la acción, sin $h a-$ cerla. La expresión no sería mimēsis.

Lo que sucede en la poética es que lo posible y verosímil se presenta no de un modo particular, sino "particularizado". Esto es lo que, según St. Croix, expresa Aristóteles al decir:

En general a qué tipo de hombres les ocurre decir o hacer tales o cuales cosas verosímil o necesariamente $[\ldots]$ aunque luego ponga nombres a los personajes, y en particular, qué hizo o qué le sucedió a Alcibíades". ${ }^{27}$

La "particularización" de lo que es en general (hos epí tò poly) es lo propio de la poesía con respecto al modo de tratar la posibilidad del mundo contingente para presentar

gún la ciencia y lo general, tal como corresponde al ámbito contingente. Cfr. G. E. M. St. Croix, "Aristotle on History and Poetry (Poetics, 9, 1451a 36-b 11)", en Rorty, op. cit., pp. 23-32.

${ }^{27}$ Po., 9, 1451b 9-11. 
una acción verosímil. Aristóteles aplica a estos particulares el calificativo de pepoíetai, que indica que "ha sido producido o fabricado". ${ }^{28}$ García Yebra traduce esta palabra por "ficticio". ${ }^{29}$ El término "ficción" no es estrictamente aristotélico, pero no resulta ajeno al modo en que Aristóteles explica el problema de la realidad poética y su finalidad como mimēsis de acciones. ${ }^{30}$

El problema que suele surgir con términos como "ficción" y "mito" se debe al uso peyorativo que se hace de ellos, ya que se emplean para referir la falsedad e inevitablemente el uso de tales palabras despierta una "sospecha" en el lector o el espectador. Esta sospecha no es gratuita. De hecho, puede ser incluso benéfica y conveniente a los fines de la poética. ${ }^{31}$

Antes que nada, hay que considerar que algo ficticio no es natural -es decir, no tiene un principio intrínseco, sino dado por otro-, pero ello no implica que no sea real de algún modo. Es una realidad que se hace. Tampoco puede decirse que el contenido de

${ }^{28}$ Cfr. H. G. Liddell, y R. Scott, op. cit., s.v., pepoiétai y poíē.

${ }^{29}$ Cfr. V. García Yebra (trad.), Poética de Aristóteles, 1992, Madrid, Gredos, pp. 159-60.

${ }^{30}$ En efecto el origen de la palabra es latino y su uso con referencia a lo artístico o literario es tardío. Ficción viene del verbo latino fingo. C. T. Lewis, C. Short, A Latin Dictionary, 1879, Oxford, Clarendon Press, s.v., fingo.

${ }^{31}$ Cfr. Woodruff, op. cit., pp. 88-9. lo ficticio sea necesariamente falso; tiene un estatuto de realidad distinto y debe comprenderse y juzgarse desde el reconocimiento de su límite originario. ${ }^{32}$ Currie señala que no toda construcción imaginativa es ficción: sólo puede llamarse estrictamente ficción a lo que se pone en común, a un acto comunicativo que se caracteriza, además por una intención clara de hacer creer sin engañar. ${ }^{33}$

De hecho, difícilmente se pretende engañar al espectador del arte. Por más realista o hiperrealista que sea una obra, tiene por lo menos la intención de sorprender, de destacar algo de la realidad, de enmarcarla, ${ }^{34}$ de modo que toda la obra se configura en este entendido. La ficción es, por así decirlo, la hipótesis de una acción en acción. El espacio es supuesto, un escenario proyectado, pero el proceso que ocurre en él -el movimiento (metabolē) - es real.Además, el contenido racional de la ficción, en

32 "La desencarnación de la realidad a través de la imagen no equivale a una simple disminución de grado. Resulta de una dimensión ontológica que no se extiende entre nosotros y una realidad qué captar, sino ahí donde el comercio con la realidad es un ritmo", E. Lévinas, "La realidad y su sombra", en La realidad y su sombra, 2001, Madrid, Trotta, p. 51 .

${ }^{33}$ G. Currie, The Nature of Fiction, 1990, Cambridge, Cambridge University Press, pp. 24-30.

${ }^{34} \mathrm{Al}$ respecto, se puede considerar lo que Danto propone con los ready mades como un "sacar de la realidad" y renovar lo cotidiano. Cfr. A. Danto, The Transfiguration of the Commonplace, 1981, Cambridge, Harvard University Press, pp. 90-5. 
NOTAS

su calidad de hipótesis, puede ser verdadero o falso, igual que el de cualquier otro silogismo en cuanto a su valor formal, aun cuando su materia no se valga sólo de elementos intelectuales, sino orécticos, sensibles y emotivos.

\section{La hipótesis de la acción}

El término aristotélico más cercano a este propósito que se describe como "ficción" es hypóthesis, en el sentido de suposición. ${ }^{35}$ Para Aristóteles, la hipótesis es una premisa supuesta que servirá para mostrar o hacer evidente (es decir, poner a la vista) algo que no tiene demostración racional. ${ }^{36}$ Una de las características más relevantes del silogismo hipotético es el hecho de que se da una convención entre las partes que discuten, es decir, que han llegado al

${ }^{35}$ Liddell y Scott lo ubican como el tercer sentido de la palabra. Además, corresponde mejor a la explicación de la poética el cuarto sentido de "presuposición" que se caracteriza desde hypokeímenon, como la presuposición de una acción, tal como ha sido propuesta antes de comenzar y, en el silogismo, como el enunciado preliminar de un hecho. Cfr. Liddell-Scott, op. cit., s.v. hypóthesis, hypotithèmi e hypókeimai. En las obras lógicas aristotélicas, la hypóthesis pertenece con mayor propiedad al ámbito de la dialéctica, el modo de la lógica propio para las cosas que pueden ser de otro modo. Se aplica sobre todo en la Retórica, pero en su carácter dialéctico es válido también para la Poética. Cfr. Po., 16, 1455a 13-6.

$$
{ }^{36} \text { A. Pr., I-30, 46a 27-8. }
$$

acuerdo de tomar una proposición como si fuera verdadera, aunque no lo sea claramente. ${ }^{37}$ Debido a la dificultad que arroja el problema que se discute (el no poder ser demostrado, como ocurre con todas las realidades que pueden ser de otra manera) quienes participan en la discusión se guían por la verosimilitud.

De este modo, el estatuto de la ficción, desde el mero hecho de plantearse como una hipótesis, anuncia una vocación comunicativa que establece relaciones entre lo real y lo posible, de modo que puedan compartirse las posibilidades en los mismos términos en que se transmite la realidad..$^{38}$ La formulación hipotética de accio-

${ }^{37}$ Ibid., I-44, 50a 19, 32-3. Afirma Aristóteles en este capítulo que explicará más adelante los argumentos que concluyen por hipótesis, pero lamentablemente no realiza esta explicación en toda la obra. Cfr. M. Candel Sanmartín, (trad.) Analíticos Primeros, 1995, Madrid, Gredos, núm. 320, p. 215.

${ }^{38}$ Debido a la dificultad que arroja el problema que se discute (el no poder ser demostrado, como ocurre con todas las realidades que pueden ser de otra manera) quienes participan en la discusión se guían por la verosimilitud. Tal es el ejemplo de la Poética antes citado, donde los espectadores hacen un paralogismo aceptando el hecho de que nadie más haya tendido el arco antes que Odiseo, sin haber comprobado esto. "Pero hay también una agnición basada en un paralogismo de los espectadores, como en el Odiseo falso mensajero; pues el tender el arco y que nadie más lo hiciera es invención del poeta y una hipótesis, lo mismo que si dijera que reconocería el arco sin haberlo visto; pero que lo inventara pensando que aquél se haría reconocer por este medio, es un paralogismo". Po., 16,1455 a $13-8$. 
nes es una vía de reflexión sobre el actuar humano, sobre el modo en que el hombre se relaciona con las realidades, intelectual, volitiva y emotivamente. $^{39}$

La ficción viene a ser una mimēsis, un partir de la naturaleza de la prâxis y desde ella, desde su modo de proceder, actuar de tal modo que se revele la verdad que hay en ella. Cabría preguntarse si la verdad así mostrada corresponde una verdad práctica, a la vivencia de una auténtica prâxis téleia, cuya única distancia con lo real es su carácter de ficción. ${ }^{40}$ Para mantener la sinceridad de tal distancia, la mimēsis poética reconoce su origen en su carácter de suposición, de convención. ${ }^{41}$ Lo que en la ficción se muestra no es menos verdadero ni menos bueno ni menos bello por ser ficticio: es la verdad desplegada, buscada sin pretensión de engaño. Así, la fórmula "tal como" de la hipótesis es el reconocimiento de la mimēsis como imitadora del proceso natural de la acción que, para ser verdadera

${ }^{39}$ Es una de las razones principales de que las ficciones sean medios educativos para la formación del individuo, precisamente en aquellos campos de la existencia que no pueden memorizarse ni resolverse deductivamente. Cfr. A. López Quintás, Cómo formarse en ética a través de la literatura, 1994, Madrid, Rialp, pp. 27-31.

${ }^{40}$ Cfr. K. McLeish, Aristotle, Aristotle's Poetics, 1998, London, Phoenix, pp. 15-6.

${ }^{41}$ Currie, op. cit., pp. 49-51. y real, tiene que ser actuada, realizada y no sólo pensada. ${ }^{42}$

Esta verdad que se descubre en la vida concreta de las formas sólo se puede reconocer si se cumplen dos condiciones: primero, si se concede el protocolo de la ficción; segundo, si no se rompe la estructura interna que le da vida. ${ }^{43}$ Más que la primera condición (que es objeto de consideración de la Retórica), a Aristóteles le preocupa en la Poética la segunda: la excelencia técnica en la producción de la estructura. Me atrevo a suponer que el protocolo de la ficción no preocupa tanto a Aristóteles porque, a su juicio, todos disfrutan en mayor o menor grado de las representaciones por símismas, ${ }^{44}$ aunque no deja de señalar la reacción adversa del público cuando las obras son malas o hay en ellas alguna inconsistencia. ${ }^{45}$

La ficción, en la mayoría de los casos del arte, como tal, está concer-

${ }^{42}$ Cynthia Freeland propone que, para Aristóteles, gran parte del placer que se obtiene por la imitación consiste, precisamente, en reconocer que se trata de una imitación. Cfr. C. A. Freeland, "Plot Imitates Action", en Rorty, op. cit., p. 113.

${ }^{43}$ Cfr. McLeish, op. cit., pp. 18-9.

${ }^{44}$ Protréptico, fr. B44 Düring.

${ }^{45}$ En la Poética, Aristoteles utiliza el ejemplo de Cárcino: el poeta cuenta cómo salía el personaje Anfiarao del santuario, pero pasaba inadvertido por los espectadores y la obra fracasó porque el público no soportó el error del poeta. Po., 17, 1455a 26-30. Otro ejemplo curioso se encuentra en la Ética Nicomaquea. Aristóteles pone el ejemplo de los espectadores "que comen golosinas en los teatros, sobre todo cuando los autores que se disputan el premio son malos", EN, X-5, 1175 b. 
NOTAS

tada: incluso cuando el arte "sale al paso" como el músico que toca en una plaza o el mimo que hace un espectáculo en la calle, aquella experiencia que se encuentra sin ir a buscarla, requiere de una decisión de parte del espectador para entrar al mundo que abre el artista. En este tipo de actividades "espontáneas" es más evidente esa parte de la representación que consiste en "abrir un mundo", porque la invitación es explícita y el transeúnte elige entre quedarse o seguir su camino, libremente. En cambio, asistir al cine, ir al teatro o entrar en una galería ya supone un asentimiento por parte del espectador, que la obra podrá satisfacer o defraudar.

Si por alguna razón el oyente o el espectador no se dejan "engañar" voluntariamente por la ficción, hay un fallo en la intención comunicativa. ${ }^{46}$ Sigue habiendo arte y lo que la obra tiene de suyo sigue siendo válido, pero el espectador no puede verlo porque ignora la "puesta en común" de que todo es una suposición concertada. Para mantenerse en tal condición necesita de la virtud comunicativa, pero ésta viene dada-sobre todo-por la unidad interna de la obra, por aquello que la sostiene en el ser, que la lleva al ser y la instaura como "manifestación" de verdad posible.

Ésta es otra forma de comprender por qué dice Aristóteles, en 1451b 5-6

\footnotetext{
${ }^{46}$ Cfr. Currie, op. cit., pp. 31-4.
}

que la poesía es más universal que la historia, en tanto que es "más general y más filosófica". La verdad del ser de lo ficticio se expresa en poder reconocer lo universal en lo concreto y en lo particular. ${ }^{47} \mathrm{La}$ abstracción de las formas no es una realidad directa; sin embargo, el procedimiento genera un constructo ficticio donde comparece la verdad. ${ }^{48}$

Se debe tener en cuenta que, a pesar de tratarse de una apuesta por la acción humana, la ficción o la hypóthesis poética no es una propuesta moral ni se determina por una doctrina concreta. Lo que sigue de la propia naturaleza del arte, así considerada, apela a la realidad abierta y libre, porque así corresponde a la naturaleza de las acciones humanas. La hipótesis poética pone en observación un conflicto en desarrollo. Lo que en ella se presenta no puede tomarse como una conclusión definitiva. De hecho, con respecto a la poética es peligroso decantarse por una pura pedagogía moral, porque para Aristóteles la poética no es una escuela para espectadores sino un ámbito de vida. ${ }^{49}$ En el arte se hace posible la contemplación de la prâxis bouletikē, por medio de la ficción. ${ }^{50}$

${ }^{47}$ En el ámbito del ser como verdadero y el no ser como falso, según los sentidos del ser, en Metaph., VI-2, 1026a 35.

${ }^{48}$ Cfr. Lévinas, op. cit., p. 59.

${ }^{49}$ Cfr. López Quintás, op. cit., p. 31.

${ }^{50} \mathrm{Cfr}$. C. A. Freeland, "Plot Imitates Action", en Rorty, op. cit., pp. 115-6. 
La ficción, entonces, según la finalidad de la poética aristotélica, no es un engaño, sino una hipótesis que plantea un paradigma. Lo ejemplar no está en los elementos sensibles representados ni en los hechos concretos, tal cual son citados, sino en la enérgeia de la acción representada por estos medios. ${ }^{51}$ Por esto, el paradigma no es la anécdota o el tema de una obra, sino la acción que se mueve en esa anécdota. El paradigma, sin embargo, no tiene mayor función que la de representar una acción: su organización sintáctica se dirige exclusi- vamente a la acción representada y no a un fin ulterior en el espectador. ${ }^{52}$

En la ficción poética no se busca que el espectador actúe después del espectáculo o como consecuencia de éste, sino que actúe con el espectáculo, que vea con y en la obra, que piense con y en ella, que él mismo la haga, como los círculos magnéticos que describe el Ión de Platón, cuya fuerza une a todo el estadio. ${ }^{53}$ Esta unión es posible por la verdad práctica que se revela con la dinámica de la mímēsis en el mythos. ${ }^{54}$
${ }^{51} \mathrm{~A} 1$ respecto, es revelador el siguiente texto de Lévinas: "El conflicto entre la libertad y la necesidad en la acción humana se ofrece a la reflexión: cuando la acción se desvanece ya en el pasado, el hombre descubre los motivos que la necesitaban. Pero una antinomia no es una tragedia. En el instante de la estatua -en su porvenir eternamente suspendido-, lo trágico -simultáneamente necesidad y libertad-puede realizarse", op. cit., pp. 58-9.
${ }^{52}$ Cfr. Currie, op. cit., pp. 182-4.

${ }^{53} \mathrm{Pl}$., Ion, 535e.

${ }^{54}$ A. O. Rorty, "The Psychology of Aristotelian Tragedy", en Rorty, op. cit., pp. 8-9. 
La reproducción total o parcial de este artículo se podrá hacer si el ITAM otorga la autorización previamente por escrito. 